\title{
A Low Cost Baby Incubator Design Equipped with Vital Sign Parameters
}

\author{
Lamidi $^{1}$, Abd.Kholiq ${ }^{1}$, Muslim Ali ${ }^{2}$ \\ ${ }^{1}$ Department of Electromedical Engineering, Poltekkes Kemenkes, Surabaya, Indonesia \\ Jl. Pucang Jajar Timur No. 10, Surabaya, 60245, Indonesia \\ ${ }^{2}$ University of Gezira, University City,Wadmedani, Gezira State, Sudan \\ Email: Lamidi@poltekkesdepkes-sby.ac.id, bAbd22@poltekkesdepkes-sby.ac.id
}

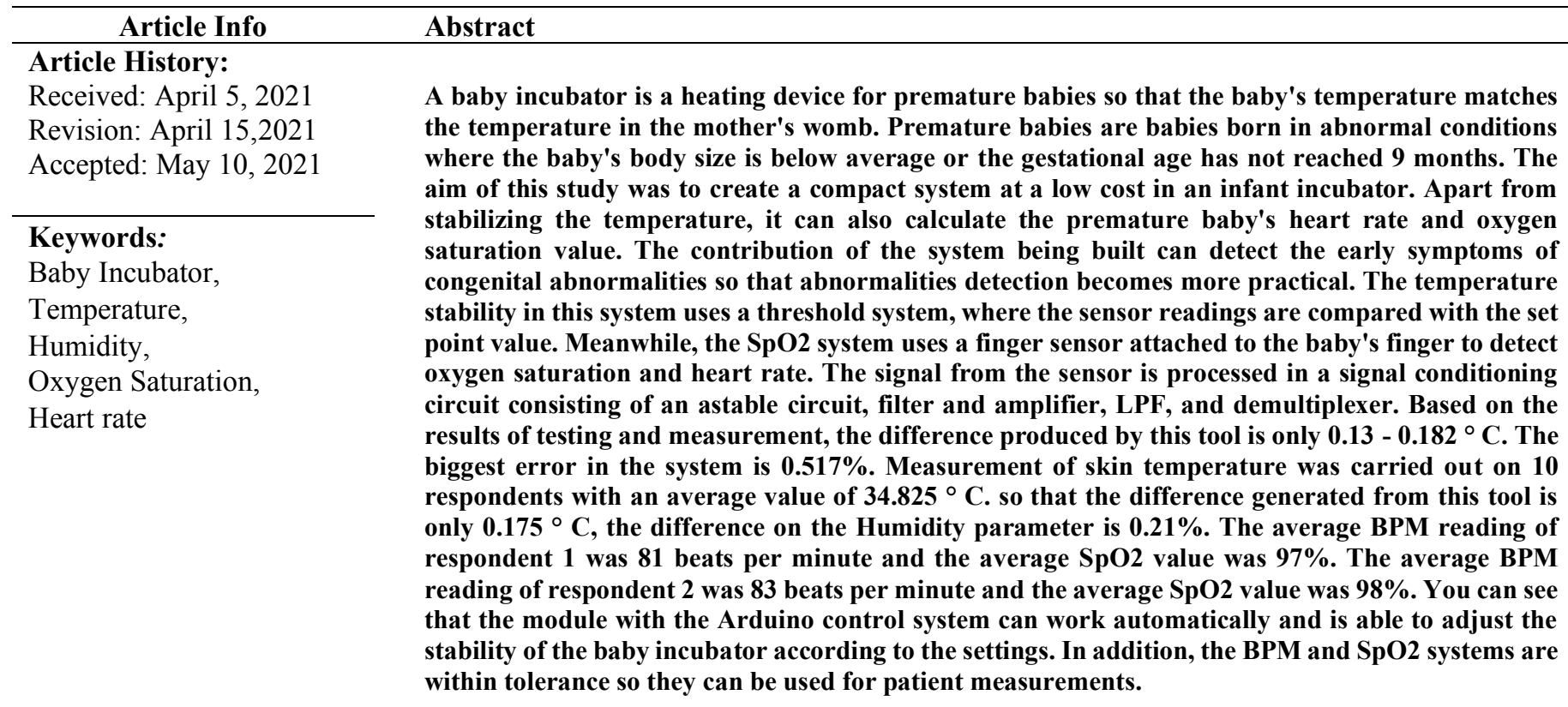

\author{
Corresponding Author: \\ Lamidi@poltekkesdepkes-sby.ac.id \\ Department of Electromedical Engineering \\ Poltekkes Kemenkes, Surabaya \\ Jl. Pucang Jajar Timur No. 10, Surabaya, 60245, Indonesia
}

This work isan open-access article and licensed under a Creative Commons Attribution-ShareAlike 4.0 International License(CC BY-SA 4.0).

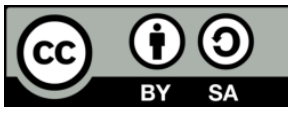

\section{INTRODUCTION}

Premature babies are babies born before the normal 36 to 37 weeks of gestation and weigh less than 2500 grams [1]. The more premature a baby is, the greater the risk of death. The high number of death they become a serious problem for public health [2]. Hypothermia often occurs in LBW (Low Birth Weight) neonates, because of the low subcutaneous fat tissue, and the relatively large body surface area. This hypothermic condition causes permanent changes in the central nervous system which ultimately leads to morality. Worse thermogulation of the baby's body is caused by an imbalance of heat production and heat loss due to the not optimal thermal environment for treatment. Leaving the warmth of the womb at birth, newborns are wet finds himself in a much colder environment [3]. As a result, the ability to avoid excessive heat loss to the environment and maintain a weak body temperature [4]. In addition, premature babies who require special care because some vital organs, biochemical systems and enzymes cannot develop adequately, or because fetal growth may be impaired [5] or can also be hampered by diseases with bad conditions such as hypoxia (below normal oxygen levels) [6]. 
Indonesian Journal of Electronics, Electromedical, and Medical Informatics (IJEEEMI)

Vol. 3, No. 2, May 2021, pp. 53-58

DOI:10. 35882/ijeeemi.v3i2.3

ISSN:2656-8624

Premature babies need special attention to keep the baby alive. One of the procedures to keep a premature baby alive is to insert it into an incubator. Incubator is one tool to help premature babies adjust to the outside world because of the conditions in the womb is very different especially temperature conditions. The temperature in the uterus is around $36-37^{\circ} \mathrm{C}$ but in the outside world it is around $27-28^{\circ} \mathrm{C}$ [7]. Incubators are specially designed to maintain and regulate temperature for premature babies with ideal conditions. Premature babies in the incubator will avoid infection due to pollution so that people can provide a healthy environment for babies and have a fair chance of survival [8]. Incubators provide optimal temperature and humidity to newborns, babies need incubators and warmer [9][10] and provides an easier control mechanism for doctors to monitor the various parameters needed to keep babies safe [11]. To maintain the condition of the baby in the incubator so that something unwanted happens, such as the case of a scorched baby in the incubator, which is usually caused by high room temperature in the incubator which is not well controlled. It is expected the baby to remain at an appropriate temperature such as when a baby is in the womb [12].

Premature babies with breathing and heart rate problems need accurate oxygenation[13] [14]. One of the monitoring is to monitor the baby's oxygen saturation. Pulse oximetry is one of the most useful monitoring tools available today, and is the method of choice for continuous monitoring of arterial blood oxygenation [15]. Pulse oximetry is a continuous non-invasive method of monitoring oxygen saturation $\left(\mathrm{SpO}_{2}\right)$ and heart rate (BPM) to ensure that the patient is not hypoxic. The use of pulse oximetry is an effective technique for assisting patients with small changes in oxygen saturation. Continuous monitoring of arterial oxygen saturation $(\mathrm{SaO} 2)$ is urgently needed by patients in special wards and $\mathrm{SaO} 290 \%$ is the target for oxygenation of patients with critical conditions [16].

Oxygen saturation and heart rate in premature infants is very important to know because when levels of oxygen saturation in premature babies is low, be wary if there are abnormalities [17]. Measurement of oxygen saturation levels and heart rate in premature babies can help early detection of congenital abnormalities. The percentage of normal oxygen saturation in humans is the same at all age levels, namely $95 \%-100 \%$ for both newborns and the elderly. Heart rate is a parameter to indicate the condition of a person's heart, and one way to determine the condition of the heart is to know the frequency of the heartbeat. And for the value of heart rate in infants between 120-150 BPM. To measure the heart rate can be done on the arteries using photoplethysmography [18]. Pulse oximetry is a non-invasive method for measuring the percentage of hemoglobin $(\mathrm{Hb})$ that is saturated with oxygen [19]. Oxygen saturation is a measurement and calculation of the percentage of oxyhemoglobin $(\mathrm{HbO} 2)$ in arterial blood vessels, oxygen saturation is defined by the ratio of oxyhemoglobin and deoxyhaemoglobin [20]. Saturation is a percentage of the hemoglobin that binds oxygen compared to the total amount of hemoglobin in the blood [21]. Activities excessive movement in the sensor area can interfere with an accurate $\mathrm{SpO} 2$ readings. At this time, we monitor premature babies using a patient monitor. Serves to determine whether to monitor the level of oxygen saturation in the blood (SpO2) and heart rate per minute (Bpm) in premature babies to know or be aware that premature babies have abnormalities or not.

Based on the above problems, the purpose of this study is to measure oxygen saturation and heart rate based on LCD to calculate oxygen saturation values and heart rate in premature babies who can show early symptoms of congenital abnormalities when the measurement results are abnormal, so that measurements are more practical and measurements can be made. done together with a baby incubator.

\section{LITERATURE REVIEW}

Tamanna et al., 2012 conducted a study design of an enhanced temperature control system for neonatal incubator. The advantage of this research is that the on off control will keep the incubator temperature at the desired temperature level and remain constant [22]. In 2014 Arief Hendra conducted a comparative study of the accuracy of temperature and humidity measurements between the DHT11 and DHT22 sensors, a comparative study on the Atmel AVR and Arduino platforms that indoor measurements using the DHT22 temperature sensor showed better accuracy than DHT11. DHT11 measurements gave slightly better results for temperature parameters, while for humidity parameters, DHT22 actually showed better results even with a slight difference [17]. In 2015 Hitu et al conducted a study on controlling of temperature and humidity for an infant incubator using a microcontroller. Research using the DS18B20 temperature sensor response time is very fast and unstable[18]. In 2017 feki et al gpc temperature control of a simulation model of infant-incubator and practice with arduino board. This study says that GPC control is better in the absence of a baby [19]. In 2019 Widhihada et al conducted research on the robust PID control system of temperature stability and humidity on infant incubator based on Arduino at Mega 2560.This research has used the PID system, but when there is a load the error value is greater than when there is no load. The LM35 sensor has high stability for the temperature setting system[20]. This tool is not equipped with SPO2 and BPM parameters because premature babies often experience breathing problems or premature apnea. Apnea is a condition when it stops and often occurs for a few seconds which is then accompanied by an extreme decrease in oxygen uptake. One of the causes of apnea is slowed heart rate and breathing in premature babies is not yet fully completed. Based on the author's observations, the writer wants to develop a Baby Incubator equipped with SPO2 and BPM (temperature and humidity).

\section{MATERIALS AND METHODS}

\section{A. Research Setting}

Data collection in this study was carried out on all temperature setting parameters ranging from $32^{\circ} \mathrm{C}$ to $36^{\circ} \mathrm{C}$ and humidity readings on the baby incubator device. The skin

\section{Accredited by Ministry of Research and Technology /National Research and Innovation Agency, Indonesia Decree No: 200/M/KPT/2020}

Journal homepage: $\underline{\text { http://ijeeemi.poltekkesdepkes-sby.ac.id/index.php/ijeeemi }}$ 


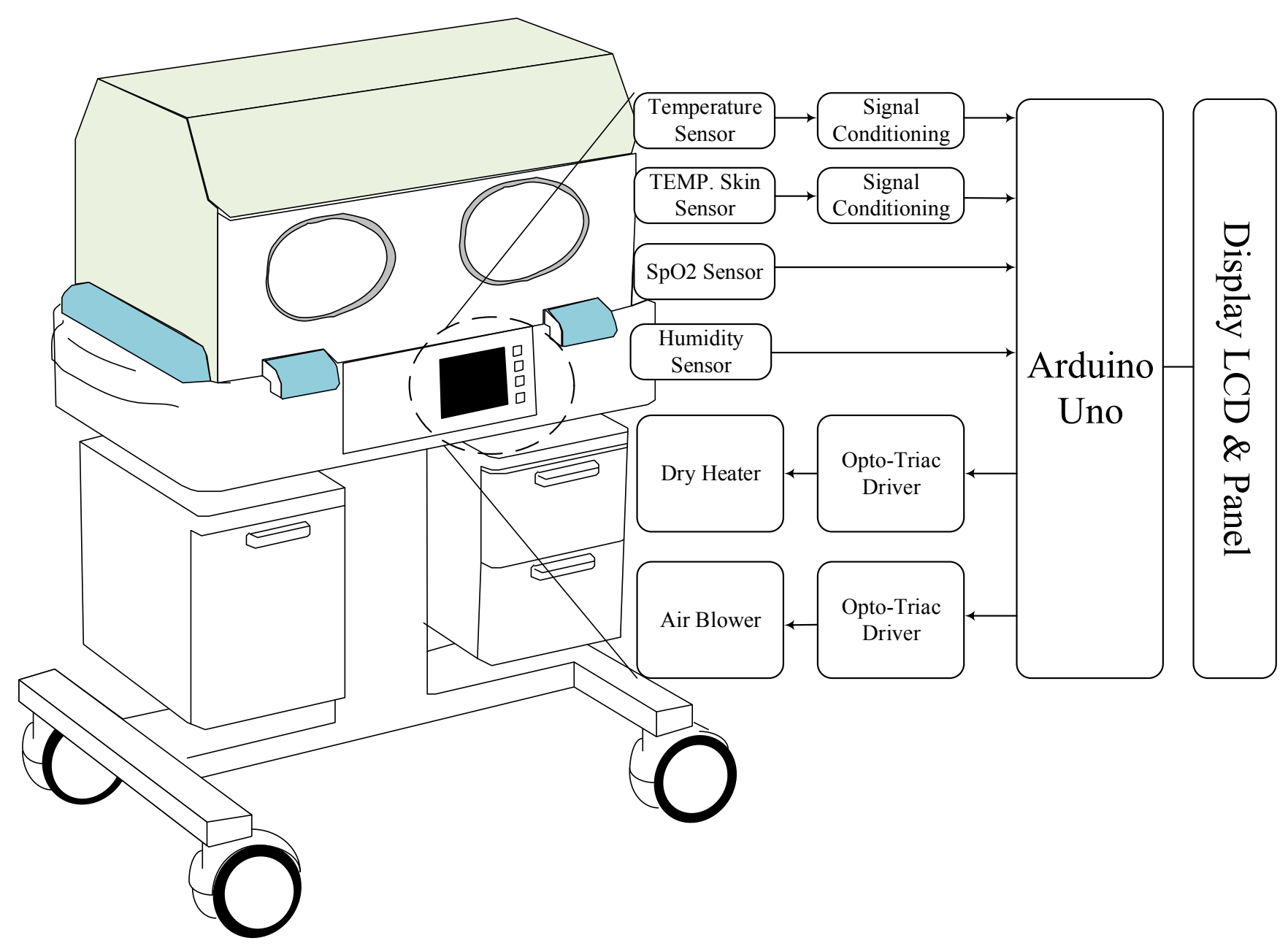

Fig. 1. The system design of baby incubator with Spo2 and BPM

temperature was measured using the temperature of the patient's right abdomen.

\section{1) Materials and tools}

This study used the LM35 sensor as a temperature reading in the infant incubator chamber instrument. The DHT22 sensor reads the incubator's humidity value, and the thermistor is used to detect the temperature on the baby's skin. Oxygen saturation and bpm in this system are detected by the $\mathrm{SpO} 2$ sensor. The filament used is 300 watts.

\section{2) Research}

In this study, after the infant incubator module was made, measurements of temperature and humidity were set on the infant incubator device, testing the patient's skin temperature, oxygen saturation value and BPM. Tests and measurements were carried out in a room with a temperature ranging from $25-27^{\circ} \mathrm{C}$.

\section{B. Block Diagram}

In this study, the LM35 sensor as a room temperature sensor will read room temperature. The LM35 sensor sends data in the form of analog data on pin A0 which is connected to a buffer circuit which functions to keep the input value the same as the output. If the room temperature is smaller than the setting then the heater is on and vice versa if the room temperature is more than the setting then the heating performance is off. The skin temperature sensor will read the patient's skin temperature by dividing the voltage read by Arduino. The skin sensor is placed on the right abdomen. The DHT22 sensor has read the humidity in the incubator compartment. The $\mathrm{SpO} 2$ sensor detects the baby's oxygen saturation and BPM, where the sensor is placed on the baby's finger. All parameter values are displayed on the $4 \times 20$ character LCD screen. The bell rings if an error occurs due to overheating which can endanger the life of the baby. The complete design is shown in Fig. 1

\section{Flowchart}

The incubator is turned on then the temperature sensor, humidity sensor, and oxygen saturation sensor initialize the data. 
Furthermore, the temperature and humidity sensor values are displayed on the 20x4 LCD and make room temperature settings that will activate the heater. If the room temperature is less than the setting temperature, the heater will stay on and if the room temperature exceeds the setting temperature, the heater will turn off. The finger sensor will detect ADC data in the form of ACred, ACir, DCred, and DCir. If the signal is not detected, the sensor will re-detect and if detected, analog data will be processed on the LCD to display the data value in the form of a presentation of oxygen saturation levels in the blood ( $\mathrm{SpO} 2)$ and beat per minute (BPM). And the process is complete (Fig. 2).

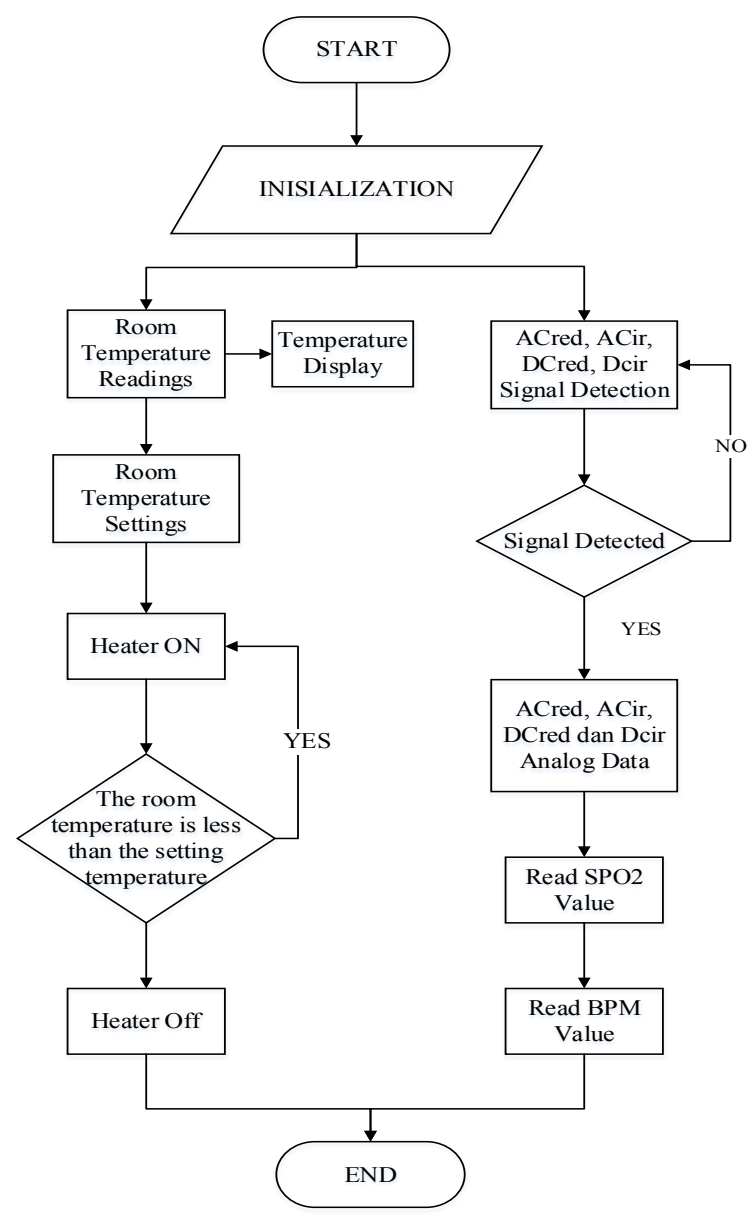

Fig. 2. Flowchart of baby incubator with Spo2 and BPM

\section{RESULTS AND DISCUSSIONS}

In this study, the baby incubator was carried out by measuring the temperature setting on the reading of the instrument, the skin temperature was carried out on the patient directly, and the humidity reading was carried out in the incubator chamber.

1. Design

The design of this baby incubator, the control used in the SSR and relay circuit only requires the heater driver circuit, the rest is set on the program and controlled on the Arduino.

\section{Program Listing}

In this study using the Arduino program for readings on the LM35 sensor, thermistor sensor, and DHT22 sensor in program listing 1 . The program to display the sensor readings on the 20 $\mathrm{x} 4$ character LCD is shown in program listing 2 .

Program listing 1. Program for sensor reading

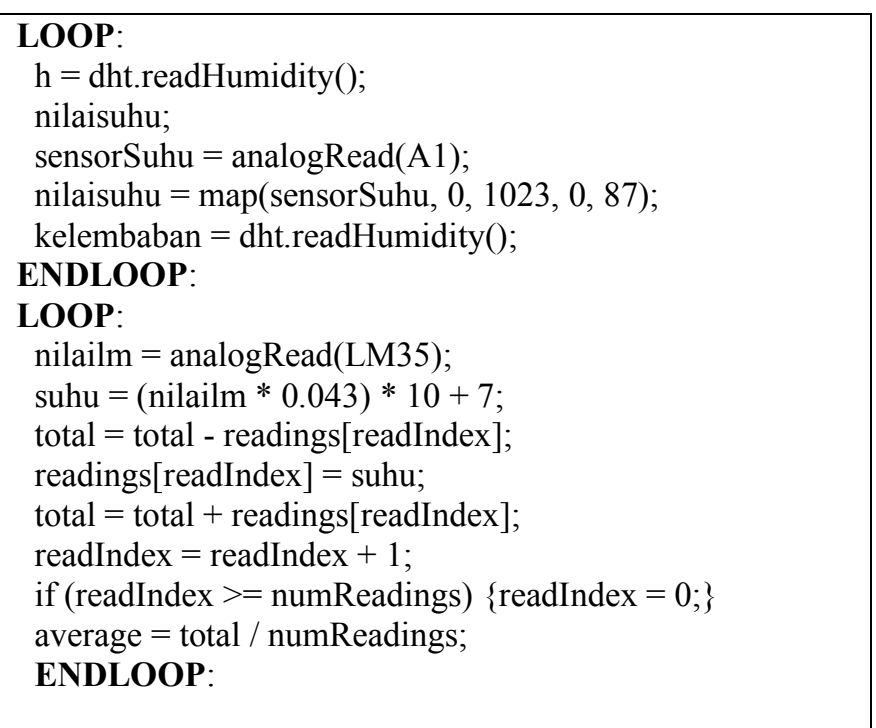

Program Listing 2. Program for SPO2 reading

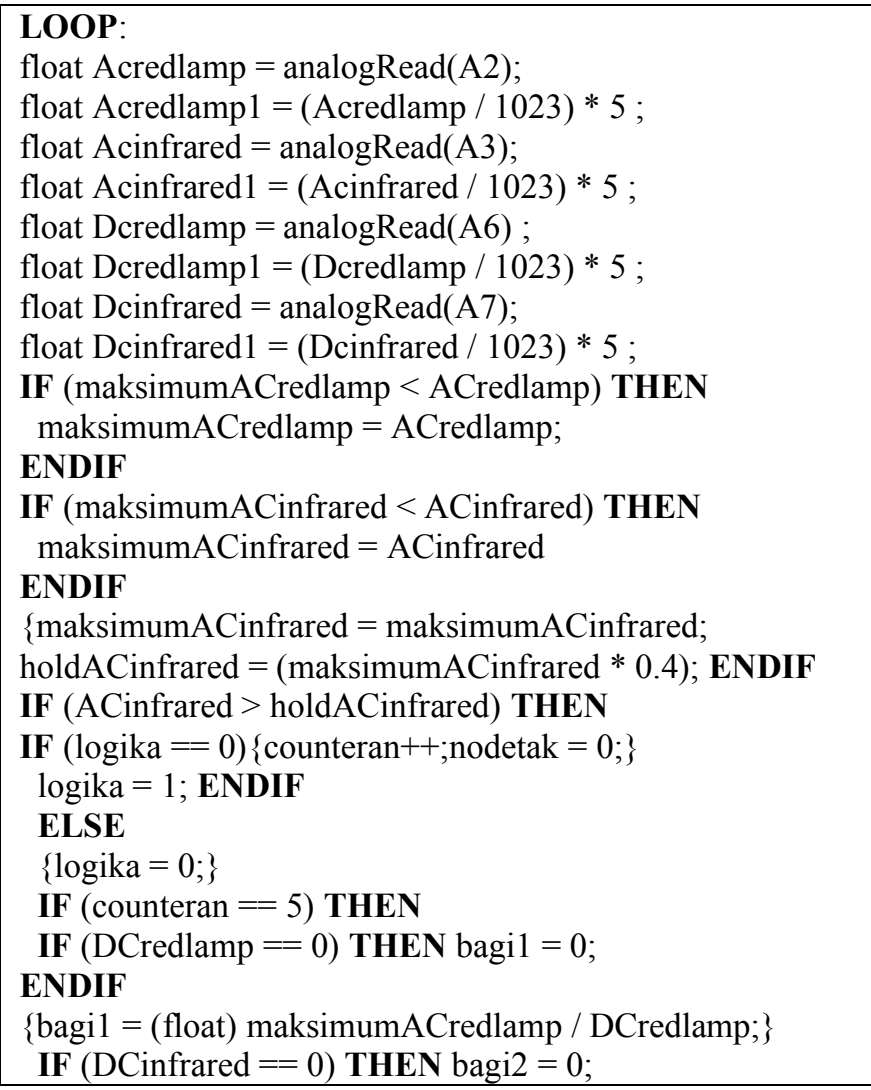


Indonesian Journal of Electronics, Electromedical, and Medical Informatics (IJEEEMI)

Vol. 3, No. 2, May 2021, pp. 53-58

DOI:10. 35882/ijeeemi.v3i2.3

ISSN:2656-8624

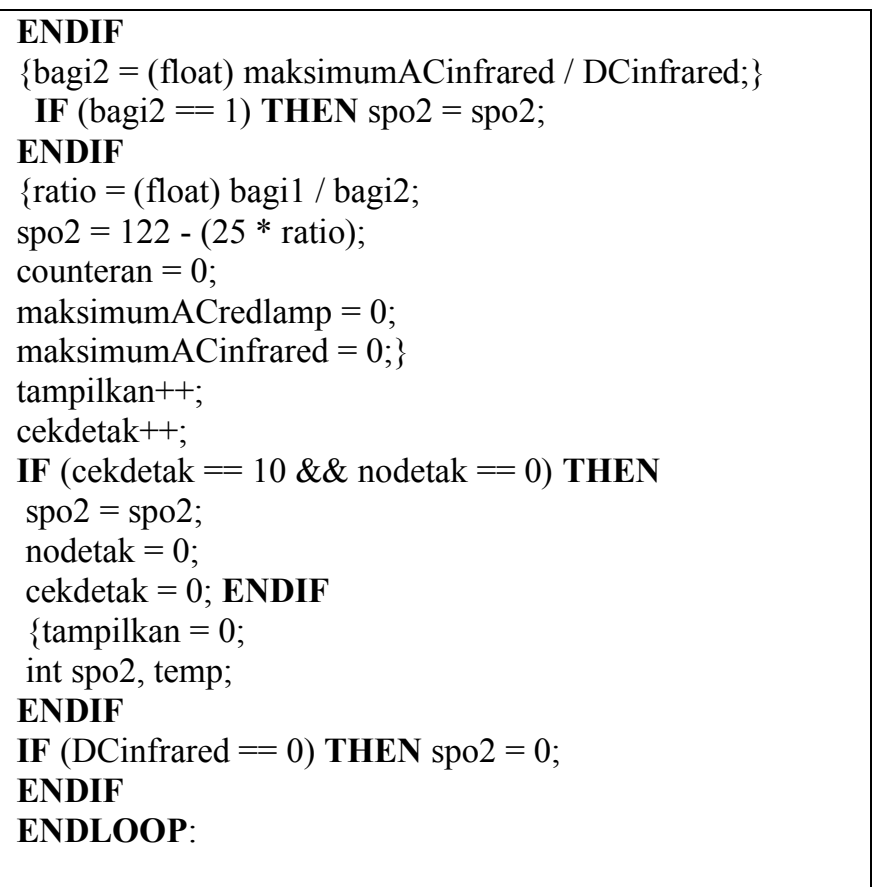

3. Measurement Result of The Baby Incubator Tool

The results of the measurement of the baby incubator were carried out at the setting temperature of the reading on the instrument. The results are shown in Table 1.

TABLE I. MEASUREMENT RESUlT OF SENSOR TEMPERATURE

\begin{tabular}{cccccc}
\hline \hline No. & $\begin{array}{c}\text { Temp } \\
\text { Setting } \\
{ }^{\circ} \mathrm{C}\end{array}$ & $\begin{array}{c}\text { Error } \\
\%\end{array}$ & $\begin{array}{c}\text { Mean } \\
{ }^{\circ} \mathrm{C}\end{array}$ & $\begin{array}{c}\text { Std } \\
\text { Dev }\end{array}$ & $\begin{array}{c}\text { P-value } \\
\text { T-test }\end{array}$ \\
\hline 1. & 32 & 0.508 & 32.163 & 0.0054 & $3.06836 \mathrm{E}-09$ \\
2. & 33 & 0.44 & 33.146 & 0.0466 & 0.000750502 \\
3. & 34 & 0.381 & 34.13 & 0.0837 & 0.038802726 \\
4. & 35 & 0.517 & 35.182 & 0.0084 & $9.11385 \mathrm{E}-09$ \\
5. & 36 & 0.412 & 36.149 & 0.0074 & $3.72598 \mathrm{E}-08$ \\
\hline
\end{tabular}

In table 1 above, the $p$-value is $<0.05$, indicating that there is a difference between the reading of the setting temperature and the design. However, the reading of the design in each setting has good data precision, so that the difference generated from this tool is only $0.13-0.182^{\circ} \mathrm{C}$. The biggest error in the system is $0.517 \%$

The results of the measurement of skin temperature were carried out on the patient's right stomach 3 times. p-value $>0.05$, thus indicating that there is no significant difference between the setting and design temperature readings. However, the reading of the design in each setting has good data accuracy, so that the difference generated from this tool is only $0.175^{\circ} \mathrm{C}$. The results of humidity measurement in the incubator room resulted in an average of $60,786 \%$.
From table 2 is the measurement result of oxygen saturation (SpO2).

TABLE II. THE RESULTS OF MEASURING SPO2 AND BPM ON THE RESPONDENT

\begin{tabular}{ccc}
\hline Respondent & $\begin{array}{c}\text { Average BPM } \\
\text { Value }\end{array}$ & $\begin{array}{c}\text { Average } \\
\text { SpO2 Value }\end{array}$ \\
\hline Respondent 1 & 81 & $97 \%$ \\
Respondent 2 & 83 & $98 \%$
\end{tabular}

In table 2 the average BPM reading of respondent 1 is 81 beats per minute and the average result of the $\mathrm{SpO} 2$ value is $97 \%$. The average BPM reading of respondents 2 was 83 beats per minute and the average $\mathrm{SpO} 2$ value was $98 \%$.

TABLE III. ROUGH OUTLINE OF COST

\begin{tabular}{|c|c|}
\hline Material & Cost (IDR) \\
\hline \multicolumn{2}{|l|}{ Permanent heating unit } \\
\hline Heating components & 400.000 \\
\hline Fan & 300.000 \\
\hline \multicolumn{2}{|l|}{ Temperature regulating unit } \\
\hline Temperature sensor and microcontroller & 250.000 \\
\hline \multicolumn{2}{|l|}{ Humidity unit } \\
\hline Humidity sensor & 100.000 \\
\hline \multicolumn{2}{|l|}{ Oxygen saturation and BPM units } \\
\hline $\begin{array}{l}\text { Oxygen saturation sensor and } \\
\text { microcontroller }\end{array}$ & 800.000 \\
\hline Total cost & 1.850 .000 \\
\hline
\end{tabular}

Table 3 provides a breakdown of the cost of the materials used to build the incubator circuit. The total projected cost is 1,850,000 Rupiah. All prices reported are based on a single price, not a bulk purchase price. The total incubator cost only reflects the cost of raw materials.

\section{CONCLUSION}

This study aimed to design a low cost infant incubator with complete vital signs. In addition, the aim of this study was to measure oxygen saturation and LCD-based heart rate to calculate oxygen saturation values and heart rate in preterm infants. So that it can show early symptoms of congenital abnormalities if the measurement results are abnormal. in addition, so that the measurement is more practical with the compact system in the infant incubator. The LM35 and DHT22 sensors integrated with the Arduino have worked well and are able to monitor the temperature of the incubator so that there is stability at the set temperature. As for the error at room temperature is $0.15^{\circ} \mathrm{C}$, the difference on the skin sensor is 0.17 ${ }^{\circ} \mathrm{C}$, the difference on the Humidity parameter is $0.21 \%$, the average $\mathrm{SpO} 2$ parameter is $98 \%$, and the average BPM parameter is 82 beat per minutes. In further research, we can make a baby incubator by adding a vital sign monitor parameter

\section{Accredited by Ministry of Research and Technology /National Research and Innovation Agency, Indonesia Decree No: 200/M/KPT/2020}

Journal homepage: http://ijeeemi.poltekkesdepkes-sby.ac.id/index.php/ijeeemi 
based on internet of thing technology that a premature baby needs to be more compact.

\section{REFERENCES}

[1] N. S. Joshi, S. R. Patil, R. K. Kamat, and P. K. Gaikwad, "Wireless monitoring of relative humidity inside infant incubator N.S.," Int. J. basic Appl. Res., vol. 7 , no. 11 , pp. $39-46$.

[2] E. J. L. Costa et al., "Humidity control system in newborn incubator," 19th IMEKO World Congr. 2009, vol. 4, pp. 2577-2581, 2009.

[3] D. Pandya, J. Parmar, and A. Patel, "PIC Microcontroller based baby incubator using sensors," Int. Res. J. Eng. Technol., vol. 4, no. 3, pp. 1906-1910, 2017.

[4] R. A. Wahyuono, R. Hantoro, and G. Nugroho, "Study on Dry Heat Loss of a Very Low Birth Weight ( VLBW ) Newborn Nursed in an Infant Incubator with Overhead Screen," Proceeding 13th Semin. Intell. Technol. Its Appl., pp. 3-8, 2012.

[5] A. H. Muosa, "Wireless Controland Monitoring Systemfor Premature Infant IncubatorEnvironment," $J$. Coll. Educ. pure Sci., vol. 7, no. 4, pp. 28-39, 2017.

[6] P. Ele, J. B. Mbede, and E. Ondoua, "Parameters Modelling and Fuzzy Control System of Neonatal Incubators," SETIT 2009, pp. 6-11, 2009.

[7] A. W. Kale, A. H. Raghuvanshi, P. S. Narule, P. S. Gawatre, and S. B. Surwade, "Arduino Based Baby Incubator Using GSM Technology," Int. Res. J. Eng. Technol., pp. 462-465, 2018.

[8] T. S. U. Suriya, S. Hemalatha, and R. Monika, "An Adaptive Generalized Predictive Control for Temperature and Humidity inside an Incubator," Int. J. Sci. Res. Dev., vol. 3, no. 01, pp. 645-647, 2015.

[9] Z. S. A. Rahman and F. S. A. Hussain, "Smart Incubator controller," Int. Res. J. Eng. Technol., vol. 4, no. 3, pp. 2501-2509, 2017.

[10] D. D. Vyas, "System for Remote Monitoring and Control of Baby Incubator and Warmer," no. May 2016, 2017.

[11] M. Ali, M. Abdelwahab, and S. Awadekreim, "Fuzzy Logic Control in Air Temperature and Skin Temperature in the Infant Incubator," Int. J. Comput. Sci. Manag. Stud., vol. 23, no. 01, pp. 10-13, 2016.

[12] M. Heater, B. In, and B. Incubators, "Desya Oktaviana,* Yuli Munandar Kolewora."

[13] B. Mallick and A. K. Patro, "Heart Rate Monitoring System Using Finger Tip Through Arduino and Processing Software," Int. J. Sci. Eng. Technol. Res., vol. 5, no. 1, pp. 1-4, 2016.

[14] B. Mallick and A. K. Patro, "International Journal of Science, Engineering and Technology Research (IJSETR)," Hear. Rate Monit. Syst. Using Finger Tip Through Arduino Process. Softw., vol. 5, no. 1, pp. 8489, 2016, doi: 10.1107/S0108767392008328.
[15] R. R. Adiputra, S. Hadiyoso, and Y. Sun Hariyani, "Internet of things: Low cost and wearable $\mathrm{SpO} 2$ device for health monitoring," Int. J. Electr. Comput. Eng., vol. 8, no. 2, pp. 939-945, 2018, doi: 10.11591/ijece.v8i2.pp939-945.

[16] E. Jahan, T. Barua, and U. Salma, "an Overview on Heart Rate Monitoring," Int. J. latest Res. Sci. Technol., vol. 3, no. 5, pp. 148-152, 2014.

[17] S. P. von Steinburg et al., "What is the "normal' fetal heart rate?," PeerJ, vol. 2013, no. 1, pp. 1-15, 2013, doi: $10.7717 /$ peerj. 82 .

[18] T. K. Mishra and P. K. Rath, "Pivotal role of heart rate in health and disease," Journal, Indian Acad. Clin. Med., vol. 12, no. 4, pp. 297-302, 2011.

[19] Y. C. Lu et al., "Reevaluating reference ranges of oxygen saturation for healthy full-term neonates using pulse oximetry," Pediatr. Neonatol., vol. 55, no. 6, pp. 459-465, 2014, doi: 10.1016/j.pedneo.2014.02.004.

[20] Konica Minolta Sensing Inc., "How to Read Blood Oxygen Saturation," pp. 15-16, 2006.

[21] J. G. Pak and K. H. Park, "Advanced Pulse Oximetry System for Remote Monitoring and Management," $J$. Biomed. Biotechnol., vol. 2012, p. 930582, 2012, doi: 10.1155/2012/930582.

[22] T. A. Tisa, Z. A. Nisha, and A. Kiber, "Design of an Enhanced Temperature Control System for Neonatal Incubator," Bangladesh J. Med. Phys., vol. 5, no. 1, pp. 53-62, 2012, doi: 10.3329/bjmp.v5i1.14668. 